\title{
Psychiatric Disorders among Suicidal Behavior Patients Attending Mental Health Facilities: A Descriptive Cross- sectional Study
}

\author{
MS ISLAM ${ }^{\mathrm{a}}$, SAA MAMUN $^{\mathrm{b}}$, MM HAQUE $^{\mathrm{c}}, \mathrm{NM} \mathrm{KHAN}^{\mathrm{d}}$, MH RASHID ${ }^{\mathrm{e}}$, \\ RK SINGHA $^{\text {f }}$, MF ABEDIN ${ }^{\mathrm{g}}$, MN UDDIN ${ }^{\mathrm{h}}$
}

\begin{abstract}
Summary:
Background: Suicide is a leading cause of death worldwide. This is the first study in Bangladesh to find out the psychiatric morbidity profile and suicidal behavior. The study was aimed to delineate the types of suicidal behavior and the psychiatric morbidity profile, and sociodemographic status of patients.
\end{abstract}

Methods: A descriptive cross-sectional study was done in Depatrment of Psychiatry, Cumilla Medical College, Cumilla from October 2015 to March 2017. A total 120 patient aged 9 to 40 years who fulfilled the enrolment criteria included in the study. The Composite International Diagnostic Interview (CIDI) module was used to assess the suicidal behavior. DSM-5 was used to diagnose the psychiatric disorders. Semi structural questionnaire were used for collecting information about the risk factors for psychiatric morbidity and sociodemographic information.

Result: Of 120 suicidal behavior patients' psychiatric disorders was 65\%. Among suicidal behavior patients neurotic disorders was 19\%, psychotic disorders was 15\%, personality disorders was 39\% and others disorder was $27 \%$. Among 78 psychiatric patients borderline personality disorder was $25.64 \%$, adjustment disorders were $15.38 \%$, mood disorders were $11.53 \%$, psychotic disorder was

a. Dr. Md. Shahedul Islam, Associate Professor, Dept. of Psychiatry, Cumilla Medical College, Cumilla.

b. Dr. Sk. Abdullah Al Mamun, Registrar, Dept. of Medicine, Rajshahi Medical College Hospital, Rajshahi.

c. Dr. Md. Mosharul Haque, Junior Consultant (Cardiology), UHC, Beanibazar. Sylhet.

d. Dr. Niaz Mohammad Khan, Associate Professor, Dept. of Psychiatry, OSD, DGHS, Mohakhali, Dhaka.

e. Dr. Md. Harun Ar Rashid, Associate Professor, Dept. of Psychiatry, Cumilla Medical College, Cumilla.

f. Dr. Ramendra Kumar Sinha, Associate Professor and Head, Dept. of Psychiatry, M A G Osmani Medical College, Sylhet.

g. Dr. Mohammed Forhad Abedin, Resident Physician, Cumilla Medical College Hospital, Cumilla.

h. Dr. Md. Nizam Uddin, Professor and Head, Dept. of Psychiatry, Cumilla Medical College, Cumilla.

Address of Correspondence: Dr. Md. Shahedul Islam, Associate Professor, Dept. of Psychiatry, Cumilla Medical College, Cumilla. Mobile: 01712261296,01719516598.E-mail:dr.shahedislam@gmail.com Received: 4 March, 2018

Accepted: 13 March, 2019
7.69\%, multiple personality disorder and oppositional defiant disorder were $6.42 \%$, hystrionic personality disorder and substance use disorder were $3.84 \%$, antisocial personality disorder, conduct disorder and anxiety disorder were $2.57 \%$, and composite disorder was $11.53 \%$. Among suicidal behavior in psychiatric patients suicidal ideation was 54, suicidal plan was 13 , suicidal attempt was 45 , ideators only proceeded to plan was 17 , ideation to attempt was 59. Among suicidal behavior in total 120 participants suicidal ideation was 84 , suicidal plan was 19 , suicidal attempt was 56, ideators only proceeded to plan was 26 , ideation to attempt was 76, planned attempt was 14 and impulsive attempt was 62. Most of the suicidal behavior participants were female (77.5\%) and age group of $<24$ years $(60 \%)$.

Conclusions: Psychiatric disorders are important risk factors for the onset and persistence of suicidal behaviour, with this risk being the greatest in childhood, and early adult.

Key Word: Suicide, Interpersonal Conflicts, Composite International Diagnostic Interview (CIDI).

(J Bangladesh Coll Phys Surg 2019; 37: 130-134)

DOI: https://doi.org/10.3329/jbcps.v37i3.41735

\section{Background}

Suicide is the primary emergency for the mental health professional, with homicide and failure to diagnose an underlying potentially fatal medical illness representing others. Suicide is a major public health problem and impossible to predict precisely. Numerous clues can be seen, which are enumerated in this section. Suicide also needs to be considered in terms of the devastating legacy that it leaves for those who have survived a loved one's suicide, as well as the ramifications for the clinicians who cared for the decedents. ${ }^{1}$ Etiology of suicide is still not well understood. Mental disorders are important risk factors for suicidal behaviour. Environmental or experiential factors also contribute to the onset and suicidal behaviours. ${ }^{2}$ This is the first study in Bangladesh to find out the psychiatric morbidity profile and and suicidal behavior. 
Suicide is derived from the Latin word for self-murder. It is a fatal act that represents the person's wish to die. There is a range, however, between thinking about suicide and acting it out. Some persons have ideas of suicide that they will never act on; some plan for days, weeks, or even years before acting; and others take their lives seemingly on impulse, without premeditation. Lost in the definition are intentional misclassifications of the cause of death, accidents of undetermined cause, and so-called chronic suicide for example, death through alcohol and other substance abuse and consciously poor adherence to medical regimens for addiction, obesity, and hypertension. ${ }^{3}$

Suicide death rates increased adolescent and decreased elderly rates for certain subpopulations during the last century. This scenerio was remained constant; averaging about 12.5 per 100,000 through the 20 th century and into the 21 st. Suicide rate for those 15 to 24 years of age has increased two- to threefold. Suicide is currently ranked the 8th overall cause of death in the United States, after heart disease, cancer, cerebrovascular disease, chronic obstructive pulmonary disease, accidents, pneumonia, influenza, and diabetes mellitus. ${ }^{4}$ Suicide rates in the United States are at the midpoint of the rates for industrialized countries as reported to the United Nations. The prime suicide site of the world is the Golden Gate Bridge in San Francisco, with more than 800 suicides committed there since the bridge opened in 1937.5

\section{Methods:}

A descriptive cross-sectional study was done in Depatrment of Psychiatry, Cumilla Medical College, Cumilla. All cases were selected from patients attending at Comilla Medical College Hospital and Private Mental Health Facilities in Cumilla City from October 2015 to March 2017. Duration of study was one and half year. Total 142 participants were approached for interview. Considering inclusion and exclusion criteria finally 120 suicidal behavior patients who fulfilled the enrolment criteria were included in the study. The participant's age was 9 years and older living in households or in hostel accommodation. All racial and ethnic groups were represented.

The Composite International Diagnostic Interview (CIDI) module on suicidality was used to assess the age of first onset, age of most recent episode, lifetime occurrence of suicidal ideation, suicide plans and suicide attempts. The CIDI is a structured interview for psychiatric diagnosis. The first version of the CIDI was published in 1988 by WHO. It has been periodically updated to reflect the changing diagnostic criteria of DSM and ICD. It can be administered by those who are not clinically trained and can be completed in a short amount of time. ${ }^{6}$ Suicidal ideation, suicide plans and suicide attempts were assessed with questions such as "Have you ever seriously thought about committing suicide? Have you ever made a plan for committing suicide?" and Have you ever attempted suicide?" respectively. Ideators only proceeded to answer questions about plans ("Have you ever made a plan for committing suicide? and attempts ("Have you ever attempted suicide?"). To get a better understanding of the progression from ideation to attempt, the outcomes considered in this study were: suicide attempts in the total sample, suicide ideation in the total sample, suicide plans among ideators, suicide attempts among ideators with a plan (planned attempts) and suicide attempts among ideators in the absence of a plan (unplanned or impulsive attempts). DSM-5 was used to diagnose the psychiatric disorders. Semi structural questionnaire were used for collecting information about the risk factors for psychiatric morbidity and sociodemographic information. Following categories of psychiatric disorders were considered: personality disorders, adjustment disorders, anxiety disorders, mood disorders, oppositional defiant disorder, conduct disorder, substance use disorders, composite disorders and others disorders. All collected data were checked and verified thoroughly for consistency as well as for completeness. Finally appropriate statistical analysis was done with SPSS version 19 to see the trends of the data. Frequency tables, summary tables and appropriate graphs were prepared to describe the population characteristics and study finding.

\section{Results:}

A participation rate was found $77.5 \%$ female and $22.5 \%$ male. Age range was 9-40 years. A psychiatric disorder was $78(65 \%)$. Majority of the participants were student and unmarried, and come from low and middle class families. 


\section{Table-I}

Distribution of respondents by sociodemographic characteristics $(n=120)$

Characteristics

Age (in years)

$\begin{array}{llc} & 18-24 & 48(40 \%) \\ & >24-32 & 28(23.33 \%) \\ & >32-40 & 20(16 ‘ 67 \%) \\ \text { Sex } & \text { Male } & 27(22.5 \%) \\ \text { Religion } & \text { Female } & 93(77.5 \%) \\ & \text { Islam } & 104(86.66 \%) \\ & \text { Hindu } & 15(12.5 \%) \\ & \text { Buddis } & 1(.87 \%)\end{array}$

Educational status

Occupation

Marital status

Famiy pattern

Habitat

\begin{tabular}{llc} 
& Urban & $51(42 ‘ 5 \%)$ \\
Socioeconomical & Low class & $52(43 ‘ 33 \%)$ \\
status & Middle class & $47(39 ‘ 17 \%)$ \\
& High class & $21(17 ‘ 5 \%)$ \\
Psychiatric & Present & $78(65 \%)$ \\
disorders & & \\
\hline
\end{tabular}

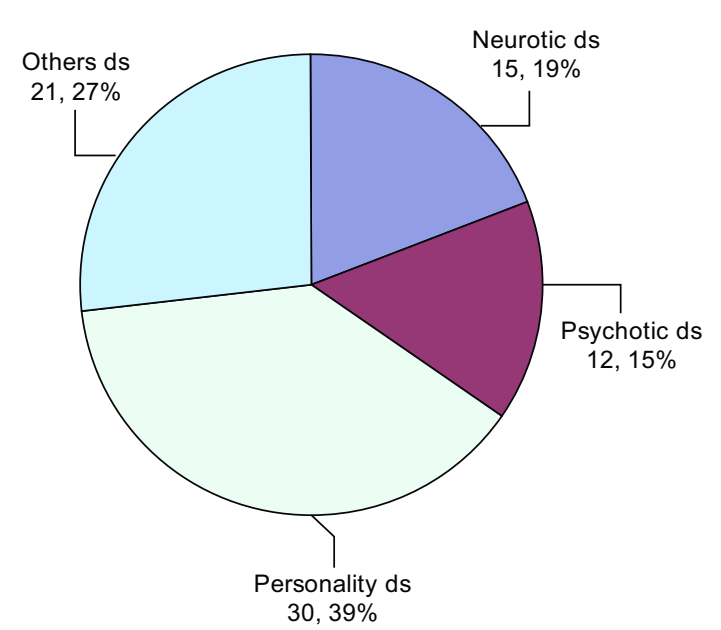

Fig.-1: Broad category of psychiatric disorders among suicidal behavior patients $(n=78)$

\section{Table-II}

Specific psychiatric disorders among suicidal behavior patients $(n=78)$

Psychiatric disorders n (\%)

Borderline personality disorder $20(25.64 \%)$

Hystrionic personality disorder $3(3.85 \%)$

Antisocial personality disorder $\quad 2(2.57 \%)$

Multiple personality disorder $\quad 5(6.42 \%)$

Mood disorders 9 (11.53\%)

Adjustment disorders $12(15.38 \%)$

Oppositional defiant disorder $\quad 5(6.42 \%)$

Conduct disorder $\quad 2(2.57 \%)$

Anxiety disorder $2(2.56 \%)$

Psychotic disorder $6(7.69 \%)$

Substance use disorder $3(3.84 \%)$

Compoite disorder $9(11.53 \%)$

Table-II showed specific psychiatric disorders among suicidal behavior respondents. Where borderline personality disorder was $25.64 \%$, adjustment disorders were $15.38 \%$, mood disorders were $11.53 \%$, psychotic disorder was $7.69 \%$, multiple personality disorder and oppositional defiant disorder were $6.42 \%$, hystrionic personality disorder and substance use disorder were $3.84 \%$, antisocial personality disorder, conduct disorder and anxiety disorder were $2.57 \%$, and compoite disorder was $11.53 \%$. 


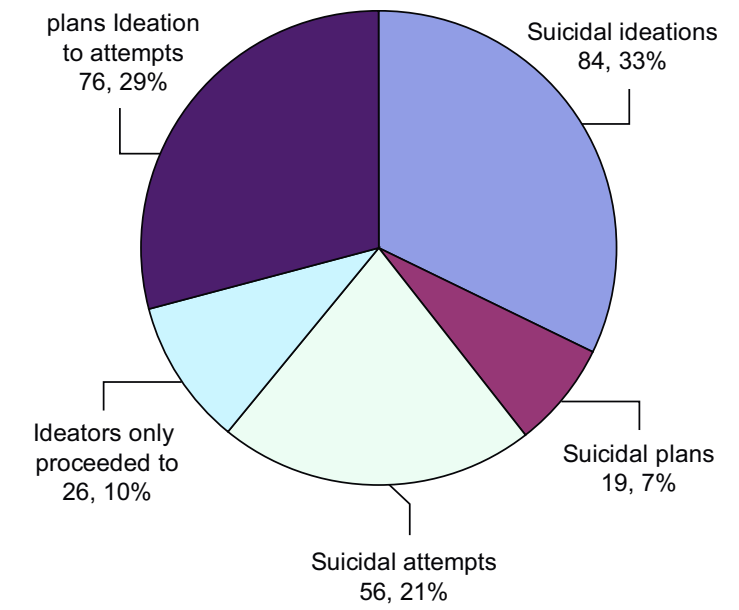

Fig.-2: Broad categorical distribution of suicidal behavior
Table-III

Categorical distribution of suicidal behavior among participants

\begin{tabular}{|c|c|c|}
\hline Suicidal behavior & $\begin{array}{l}\text { psychiatric } \\
\text { patients }\end{array}$ & $\begin{array}{c}\text { non- } \\
\text { psychiatric } \\
\text { patients }\end{array}$ \\
\hline Suicidal ideation & 54 & 30 \\
\hline Suicidal plans & 13 & 6 \\
\hline Suicidal attempts & 45 & 11 \\
\hline Ideators only proceeded to plans & 17 & 9 \\
\hline Ideation to attempts & 59 & 17 \\
\hline \multirow[t]{2}{*}{ Nature of attempts } & 8 & 6 \\
\hline & 51 & 11 \\
\hline
\end{tabular}

Table-3 showed categorical distribution of suicidal

Table-IV

\begin{tabular}{|c|c|c|c|c|c|c|c|}
\hline \multicolumn{8}{|c|}{ Distribution of suicidal behavior among specific psychiatric disorders } \\
\hline \multirow[t]{2}{*}{ Psychiatric disorders } & \multirow{2}{*}{$\begin{array}{l}\text { Suicidal } \\
\text { ideation }\end{array}$} & \multirow{2}{*}{$\begin{array}{l}\text { Suicidal } \\
\text { plans }\end{array}$} & \multirow{2}{*}{$\begin{array}{l}\text { Suicidal } \\
\text { attempt }\end{array}$} & \multirow{2}{*}{$\begin{array}{c}\text { Ideators only } \\
\text { proceeded } \\
\text { to plan }\end{array}$} & \multirow{2}{*}{$\begin{array}{l}\text { Ideation } \\
\text { to attempt }\end{array}$} & \multicolumn{2}{|c|}{ Nature of attempts } \\
\hline & & & & & & Planned & Impulsive \\
\hline Borderline personality ds. & 15 & 1 & 12 & 5 & 20 & 1 & 19 \\
\hline Multiple personality ds. & 4 & 2 & 1 & 3 & 5 & 1 & 4 \\
\hline Mood ds. & 5 & 0 & 6 & 0 & 4 & 2 & 2 \\
\hline Adjustment ds. & 9 & 4 & 6 & 4 & 7 & 0 & 7 \\
\hline Oppositional defiant ds. & 4 & 0 & 4 & 1 & 5 & 0 & 5 \\
\hline Psychotic ds. & 4 & 2 & 3 & 0 & 5 & 1 & 4 \\
\hline
\end{tabular}

behavior among psychiatric disorders respondents. Where suicidal ideation was 54, suicidal plan was 13 , suicidal attempt was 45 , ideators only proceeded to plan was 17 , and ideation to attempt was 59. Suicidal behavior among non-psychiatric respondents: where suicidal ideation was 30 , suicidal plan was 6 , suicidal attempt was 11 , ideators only proceeded to plan was 9 , and ideation to attempt was 17.

Table-4 showed categorical distribution of suicidal behavior among specific psychiatric patientss. Where suicidal behavior in borderline personality disorder suicidal ideation was 15 , suicidal plan was 1 , suicidal attempt was 12 , ideators only proceeded to plan was 5 , ideation to attempt was 20 , planned attempt was 1 and impulsive attempt was 19 . Among suicidal behavior in adjustment disorder suicidal ideation was 9 , suicidal plan was 4 , suicidal attempt was 6 , ideators only proceeded to plan was 4 , ideation to attempt was 7 , and impulsive attempt was 7 . Among suicidal behavior in mood disorder suicidal ideation was 5 , suicidal attempt was 6 , ideation to attempt was 4 , planned attempt was 2 and impulsive attempt was 2 .

\section{Discussion:}

Suicidal behavior is not a disease: rather it is the result of an adaptive difficulties, family discord, and interpersonal conflicts with peers and friends. Based on some research evidence as well as consensus, common associated psychiatric disorders included borderline personality disorders, adjustment disorders, mood disorders, anxiety disorders, oppositional defiant disorder, conduct disorder, substance use disorders and miscleneous disorders. It is important to understand and focus probable psychiatric disorders of suicidal behaviours participants. Reeviewing different literature on suicide, we tried to understand the distress of huge burden of psychiatric problem on persons with suicidal behaviours. ${ }^{5}$ Most of the suicidal behavior patients were female $(77.5 \%)$ and age group upto 24 years 
$(60 \%)$. More than a half of the respondents with suicidal behaviour experienced at least one psychiatric disorder. Personality disorder, adjustment disorders, mood disorders, and disruptive behavior disorders had stronger associations with lifetime suicide attempts. Borderline personality disorder is the commonest psychiatric disorder associated with lifetime suicide attempts and ideation. Adjustment disorders, disruptive behavior disorders, and anxiety disorder were identified as significant risk markers for lifetime suicide ideation, while borderline personality disorder and mood disorders were significantly correlated with suicidal attempts. Multiple personality disorders showed the highest prevalent of suicidal behavior both ideation and attempts. Borderline personality disorder was associated with a three fold higher risk of lifetime suicide attempts. ${ }^{7}$

The most prevalent psychiatric disorders endorsed borderline personality disorders followed by adjustment disorders, mood disorders, anxiety disorders, oppositional defiant disorder, conduct disorder, substance use disorders and composite disorders. The most prevalent suicidal behavior experienced in those with a suicide attempt as well as in those with suicidal ideation. These findings were somewhat dissimilar to other studies due to strong family bonding, cohesive family system, and strong religious believes and cultural influences, and economical variable in our country. ${ }^{8}$ These possible explanations were accepted considering mentioned factors minor variation from previous study finding.

The effect of psychotic disorders on suicidal tendencies varied over the life course. For example, personality disorders were significantly associated with suicide ideation and attempts during childhood and teen years, but not during young and later adulthood. The estimate lifetime prevalence of suicidal behavior patient's neurotic disorders was $19 \%$, psychotic disorder was $15 \%$, personality disorder was $39 \%$ and others disorder was $27 \%$. After adjusting for psychiatric illness adjustment disorders and anxiety disorder was a significant risk factor for suicidal ideation. ${ }^{9}$ These findings emphasise the need to focus particularly on suicide prevention strategies at youth. These findings were consistent partially with the previous study.

Childhood psychotic disorders emerged as a particularly robust risk factor for suicide attempts in younger participants. This was in keeping with other studies that psychotic disorders results in suicidal behaviour at a younger age. Disruptive behavior disorders emerged as risk factors for the emergence and persistence of suicidal behaviour, especially in adolescence. Single famiy pattern, divorce, marital separation and financial crisis had also been found to be associated with persistence of suicidality. ${ }^{10,11}$ These findings extend previous work carried out in other developing countries that were found psychiatric disorders to be a significant risk factor for suicidality.

\section{Limitation:}

This study was done in a single setting. So, there was a chance of biasness. This study did not represent the exact scenario of Bangladesh due to its selective zone.

Conclusions: Psychiatric disorders are important risk factors for the onset and persistence of suicidal behaviour, with this risk being the greatest in childhood, adolescence and early adult. A longotudinal follow-up study is required to give a more reliable in Bangladesh.

Conflict of Interest: The athors have none to declare.

\section{References:}

1. American Psychiatric Association. Diagnostic and Statistical Manual of Mental Disorders (DSM-5). 4th edition. APA 2014; 12: $801-6$

2. Kaplan HI \& Sadock BJ. Synopsis of psychiatry- behavioral science/clinical psychiatry.10th edition. Philadelphia: Lippincott Williams \& Wilkins 2012; 34: 898-08

3. APA practice guidelines for the assessment and treatment of suicidal behaviors. Am J Psychiatry 2003; 160:3-9.

4. Kessler RC, Berglund P, Borges G, et al. Trends in suicide ideation, plans, gestures, and attempts in the United States, 1990-1992 to 2001-2003. JAMA 2005; 293:2487-95

5. Shneidman ES. The Suicidal Mind. New York: Oxford University Press; 1996

6. Kessler RC, Andrews G et al. Composite International Diagnostic Interview short-form (CIDI). International Journal of Methods in Psychiatric Research 2015; 7 (4): 171-85.

7. Nock MK, Hwang I, Sampson NA, Kessler RC. Mental disorders, comorbidity and suicidal behavior: results from the National Comorbidity Survey Replication. Department of Psychology, Harvard University, Cambridge, MA 02138, USA 2010; 15(8): 870-75.

8. Nock MK, Borges G, Bromet EJ, Alonso J, et al. Cross-national prevalence and risk factors for suicidal ideation, plans and attempts. Br J Psychiatry 2008; 192: 98-05.

9. Bruwer1 B, Govender R, Bishop M. Association between childhood adversities and long-term suicidality among South Africans from the results of the South African Stress and Health study: a cross-sectional study.

10. Nock MK, Borges G, Bromet EJ, Cha CB, Kessler RC, Lee S. Suicide and suicidal behaviour. Epidemiol Rev 2008; 30: 133-54.

11. Borges G, Kessler RC, Walters EE. Prevalence of and risk factors for lifetime suicide attempts in the National Comorbidity Survey. Arch Gen Psychiatry 1999; 56: 617-27. 